Volume 3 Nomor 1, Februari 2018, Halaman 89-100

\title{
EFEKTIVITAS PENGGUNAAN MEDIA KARTU DOMINO UNTUK MENCAPAI TARGET HASIL BELAJAR TRIGONOMETRI
}

\section{THE EFFEVTIVENESS OF DOMINO CARD MEDIA TO ACHIEVE TRIGONOMETRY LEARNING TARGET RESULT}

\author{
Farid Gunadi \\ Universitas Wiralodra, Jln. Ir. H. Djuanda KM.3 Singaraja Indramayu 45213, \\ faridgunadi@unwir.ac.id
}

\begin{abstract}
ABSTRAK
Penelitian ini bertujuan untuk mengetahui efektivitas penggunaan media pembelajaran kartu domino untuk mencapai target hasil belajar materi trigonometri. Penelitian ini merupakan penelitian eksperimen. Populasi dalam penelitian ini adalah hasil belajar materi trigonometri siswa SMA Negeri 1 Sindang kelas X yang terbagi menjadi sepuluh kelas. Sampel penelitian diambil satu kelas dengan cara simple random sampling yaitu kelas X-2 sebagai kelas eksperimen yang pembelajarannya menggunakan media kartu domino. Dari hasil analisis data yang telah dilakukan. Uji hipotesis yang digunakan adalah uji-t satu sampel dengan KKM 75\% diperoleh $t_{\text {hitung }}>t_{\text {tabel }}$, maka tolak $\mathrm{H}_{0}$ artinya terdapat penggunaan media pembelajaran kartu efektif untuk mencapai target hasil belajar materi trigonometri yang ditargetkan.
\end{abstract}

Kata kunci: Media Kartu Domino, Hasil Belajar Materi Trigonometri

ABSTRACT

This study aims to determine the effectiveness of domino card media to achieve trigonometry material learning target results. This research is an experimental research. The population in this study is the result of learning material trigonometric students SMA Negeri 1 Sindang grade $X$ which is divided into ten grade. The sample of research taken one classes by simple random sampling that is class X-2 as experiment class which study using domino card media. From the result of data analysis that has been done, obtained the average score of learning. Hypothesis test used is t-test of one sample with Minimum Exhaustiveness Criteria $75 \%$ obtained $t_{\text {count }}>t_{\text {table }}$, then reject $H_{0}$ means there is the use of effective card learning media to achieve targeted learning outcomes of targeted trigonometric materia.

Keywords: Domino Card Media, Learning Results of Trigonometry Materials

How to Cite: Gunadi, F. (2018). Efektivitas Penggunaan Media Kartu Domino untuk Mencapai Target Hasil Belajar Trigonometri. Mathline: Jurnal Matematika dan Pendidikan Matematika, Vol.3, No.1, 89-89.

\section{PENDAHULUAN}

Hasil belajar siswa dalam matematika baik secara langsung maupun tidak langsung akan berkaitan dengan hasil belajar siswa pada mata pelajaran lainnya. Hal ini terjadi 
karenakan matematika merupakan kemampuan generik yang mendasari kemampuan lainnya, itulah sebabnya matematika sering disebut sebagai ratunya ilmu pengetahuan. Menurut Slameto (2003), "Belajar adalah suatu proses usaha yang dilakukan oleh seseorang dengan tujuan untuk memperoleh suatu perubahan tingkah laku yang baru secara keseluruhan, sebagai hasil pengalamannya sendiri dalam interaksi dengan lingkungannya".

Belajar matematika diharapkan dapat mengubah siswa dari pasif ke aktif sehingga tercipta interaksi dengan lingkungan sekitar. Pada kenyataannya banyak siswa yang mengatakan bahwa pelajaran matematika adalah salah satu pelajaran yang sangat sulit untuk dimengerti. Seperti yang diungkapkan oleh Komandoko (2009) bahwa, "Pelajaran matematika biasanya dianggap momok menakutkan bagi kebanyakan siswa. Pelajaran 'hitung-berhitung' ini kerap dianggap membuat bingung dan dianggap pelajaran yang tidak menarik. Pelajaran yang kerap dihindari seperti kerapnya untuk tidak dipelajari”. Perhitungan dalam matematika sering dihindari siswa yang kurang mampu untuk menghitung dengan baik, berbeda jika perhitungan tersebut dibuat sesuatu yang menarik minat siswa untuk belajar matematika.

Keberhasilan dalam proses pembelajaran diantaranya tidak terlepas dari persiapan siswa dan guru. Siswa yang merasa siap untuk belajar akan merasa termotivasi dan penuh perhatian untuk mengikuti proses pelajaran tersebut. Namun banyak siswa yang mengalami kebosanan dalam pembelajaran matematika, Oleh karena itu guru harus berupaya memelihara dan mengembangkan minat belajar siswanya. Beberapa guru dalam pembelajaran matematika cara penyampaiannya masih menggunakan metode pembelajaran yang berpusat pada satu arah sehingga membuat siswa jenuh untuk belajar matematika. Banyak cara yang dapat dilakukan untuk memotivasi siswa dalam belajarnya, seperti yang diutarakan Subandi (2004) bahwa, "Kegiatan yang bisa mengoptimalkan prinsip sifat merangsang dan menantang dari materi yang dipelajari dapat meningkatkan motivasi siswa dalam belajar".

Agar terjalin interaksi antara guru dengan siswa, maka seorang guru harus memperhatikan kesiapan intelektual siswa serta pemilihan media pembelajaran yang tepat dalam proses belajar mengajar. Dengan menggunakan media dalam pembelajaran matematika diharapkan dapat mempermudah siswa untuk menerima dan memahami matematika. "Media adalah perantara atau pengantar pesan dari pengirim ke penerima pesan" (Sadiman, 2003). Sedangkan Briggs yang dikutip Sadiman (2003) berpendapat bahwa "Media adalah segala alat fisik yang dapat menyajikan pesan serta merangsang siswa untuk belajar". Penggunaan media pembelajaran diharapkan dapat meningkatkan 
penyampaian informasi dari guru ke siswa secara jelas dan dengan media diharapkan siswa dapat termotivasi dalam pembelajarannya.

Keberhasilan siswa dalam belajar matematika salah satunya tergantung pada cara penyajian materi pembelajaran, banyak media pembelajaran yang dapat digunakan oleh guru pada proses belajar mengajar matematika. Gagne (Sadiman, 2003) menyatakan, "Media adalah berbagai jenis komponen dalam lingkungan siswa yang merangsang untuk belajar".

Salah satu cara penyajian materi pelajaran matematika yang diharapkan dapat menumbuhkan ketertarikan siswa untuk belajar matematika sehingga diharapkan dapat meningkatkan hasil belajar matematika adalah dengan menggunakan media pembelajaran kartu domino. Sundayana (2013) "Kartu domino digunakan untuk melatih ingatan dan pemahaman mengenai rumus-rumus pada pembelajaran Matematika”. Media kartu domino pada peneletian ini adalah cara permainan kaartu domino yang diterapkan untuk mengerjakan latihan soal. Sehingga dengan begitu siswa akan lebih tertarik dan termotivasi dalam pembelajarannya. Dalam penelitian ini tujuan media pembelajaran kartu domino adalah untuk membantu siswa menguasai pemahaman mengenai sudut istimewa trigonometri.

Kartu domino di sini bukanlah suatu kartu yang digunakan oleh orang untuk berjudi, melainkan suatu media untuk pembelajaran yang bentuknya dibuat seperti kartu domino untuk menarik minat siswa dalam belajar matematika. Konsep Pembelajaran dengan menggunakan media pembalajaran kartu domino lebih menekankan pada cara permainan kartu domino untuk memperoleh suatu kebermaknaan sehingga dapat menimbulkan minat belajar siswa.

Layaknya kartu domino kartu ini terbagi menjadi dua sisi, dalam penelitian ini sisi kartu domino yang pertama diberi soal dan sisi berikutnya diberikan salah satu alternatif jawaban. Dalam permainan kartu domino ini siswa dituntut untuk mencari tahu jawaban soal kemudian dicocokan kedalam salah satu jawaban pada kartu terbuka yang diletakan di atas meja. Permainan kartu domino ini diharapkan membuat siswa merasa terpacu untuk mengerjakan soal-soal latihan yang berada pada kartu domino. 
92 Efektivitas Penggunaan Media Kartu Domino untuk Mencapai Target Hasil Belajar Trigonometri

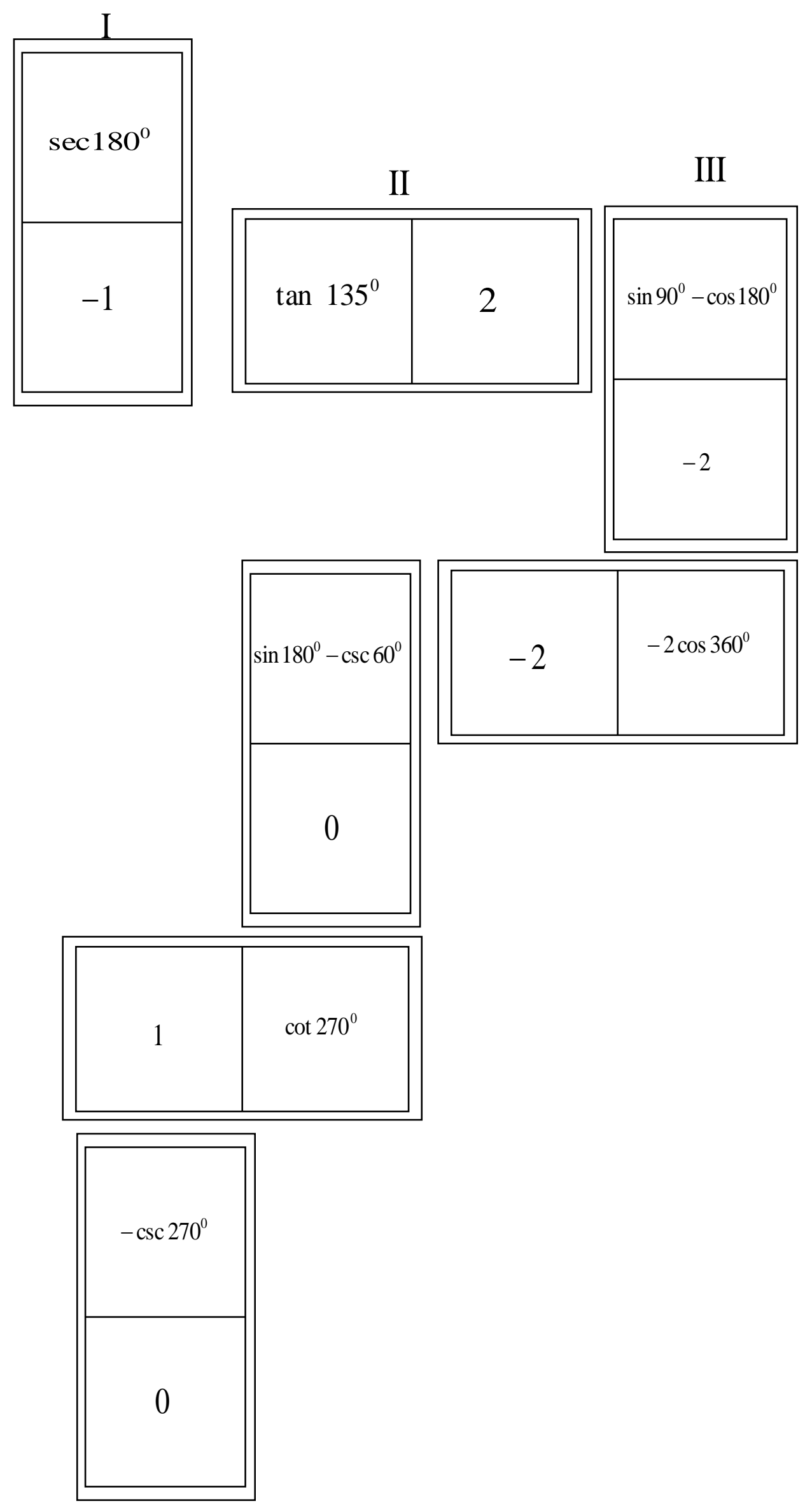

Gambar 1 Media Pembelajaran Kartu Domino 
1) Petunjuk Penggunaan

a. Pola permainan kartu ini seperti permainan kartu domino. Yang berbeda adalah yang dimuat dalam kartu berupa soal-soal dari materi pangkat bulat positif dan beberapa sisi kartu tersebut mempunyai penyelasain yang sama.

b. Bila pada kartu domino, nilai tiap sisi kartu ditentukan oleh banyaknya dot (bulatan kecil), maka pada kartu ini, nilai tiap sisi ditentukan dari penyelesaian soal-soal pangkat bilangan bulat.

c. Sisi yang berbentuk soal harus dicari dulu jawabannya setelah itu disambung dengan sisi lain yang mempunyai jawaban serupa. Contoh pada peragaan kartu di atas. Kartu II memiliki sisi tan $135^{\circ}=-1$ bawah yang digabung dengan kartu I yang sisi satunya memu memuat jawaban -1 . Kedua sisitersebut dapat disambung karena memuat jawaban yang sama.

2) Pola Permainan

a. Bentuk kelompok-kelompok siswa, setiap kelompok berjumlah maksimal 4 siswa secara random.

b. Masing-masing kelompok diberi satu set kartu domino.

c. Bagi habis seluruh kartu ke semua pemain secara merata. Pemain menyelesaikan soal-soal yang terdapat pada kartu yang mereka dapatkan.

d. Pemain yang mendapat giliran pertama, membuka sebuah kartu lebih dulu. Pemain selanjutnya mencari pada kartu yang dipegangnya yang memiliki sisi yang senilai dengan sisi kartu yang terbuka. Bila pemain yang mendapat giliran tidak memiliki kartu yang sesuai, maka pemain berikutnya yang mendapat giliran.

e. Pemain yang menang adalah pemain yang tidak memiliki kartu lagi atau pemain yang memiliki kartu paling sedikit, ketika permainan tidak dapat dilanjutkan lagi.

Materi trigonometri merupakan salah materi yang tidak diminati siswa, hal ini disebabkan banyak rumus yang harus dihafal dan perhitungannya pun sulit. Sedangkan materi trigonometri adalah salah satu materi yang penting pada tingkat sekolah menengah. Hal ini dikarenakan materi trigonometri sebagai salah satu materi pondasi untuk materimateri yang berkaitan lainnya. Dengan menggunkan media pembelajaran kartu domino diharapkan siswa dapat termotivasi agar menghafal rumus dengan baik.

Dari beberapa uraian di atas maka penulis tertarik untuk meneliti dengan rumusan masalah yaitu “Apakah Penggunaan Media Pembelajaran Karu Domino efektif untuk mencapai target Hasil Belajar Trigonometri yang Ditargetkan?”. Dari rumusan masalah tersebut tujuan penelitian ini adalah "Untuk mengetahui Apakah Penggunaan Media 
Pembelajaran Karu Domino efektif untuk mencapai target Hasil Belajar Trigonometri yang Ditargetkan".

\section{METODE PENELITIAN}

Metode Penelitian ini menggunakan jenis rancangan penelitian eksperimen dengan desain penelitian one grup-post test, dalam penelitian ini akan membandingkan antara ratarata hasil belajar trigonometri dengan KKM disekolah. Analisis penelitian ini menggunkan metode analasis one sample t-test dengan prasyarat analisis dengan uji Normalitas.

Populasi dalam penelitian ini adalah hasil belajar siswa materi trigonometri kelas $\mathrm{X}$ SMA Negeri 1 Sindang dengan menggunakan simple random sampling diperoleh kelas $\mathrm{X}$ MIPA 1 sebagai kelas eksperimen yang pembelajarannya menggunakan media kartu domino.

Instrumen yang digunakan dalam penelitian ini adalah soal essay terdiri dari lima soal yang sebelumnya divalidasi secara logis maupun empiris. Untuk validasi secara empiris menggunakan product moment Adapun rumus yang digunakan berdasarkan Suharsimi Arikunto (2002) adalah sebagai berikut.

$$
r_{X Y}=\frac{N \sum X Y-\left(\sum X\right)\left(\sum Y\right)}{\sqrt{\left[N \sum X^{2}-\left(\sum X\right)^{2}\right]\left[N \sum Y^{2}-\left(\sum Y\right)^{2}\right]}}
$$

Keterangan:

$$
r_{X Y} \quad=\text { Koefisien Product Moment }
$$

$N \quad=$ Banyaknya peserta tes

$\sum X=$ Jumlah skor item

$\sum Y=$ Jumlah skor total (seluruh item)

Sebelum diinterpretasikan, terlebih dahulu dilakukan uji koefisien korelasi dengan uji-t dengan tujuan untuk mengetahui signifikansi koefisien tersebut. Rumus uji-t untuk koefisien korelasi sebagai berikut.

$$
t=\frac{r_{X Y} \sqrt{n-2}}{\sqrt{1-{r_{X Y}}^{2}}}
$$

Keterangan:

$r_{x y}=$ Koefisien korelasi

$\mathrm{n}$ = Banyaknya subjek yang diuji. 
Adapun rumusan hipotesis untuk validitas sebagai berikut:

Ho $: \rho=0$, artinya soal dikatakan tidak valid.

Ha $: \rho>0$, artinya soal dikatakan valid.

Nilai thitung kemudian dibandingkan dengan nilai tabel dengan taraf signifikansi 0,05 dan derajat kebebasan $\mathrm{dk}=\mathrm{n}-2$, dengan kriteria:

Terima Ho dan tolak Ha jika $t_{\text {hitung }} \leq \mathrm{t}_{\text {tabel }(\alpha, \mathrm{dk})}$, soal tidak valid.

Tolak Ho dan terima Ha jika $t_{\text {hitung }}>t$ tabel $(\alpha, \mathrm{dk})$, soal valid.

Untuk mengetahui kategori koefisien validitas digunakan kriteria sebagai berikut.

Tabel 1 Klasifikasi Koefisien Validitas

\begin{tabular}{cc}
\hline Nilai $\mathbf{r}$ & Interpretasi \\
\hline $0,80<r_{X Y} \leq 1,00$ & Sangat Tinggi \\
$0,60<r_{X Y} \leq 0,80$ & Tinggi \\
$0,40<r_{X Y} \leq 0,60$ & Sedang \\
$0,20<r_{X Y} \leq 0,40$ & Rendah \\
$0,00<r_{X Y} \leq 0,20$ & Sangat Rendah \\
$r_{X Y} \leq 0,00$ & Tidak Valid \\
\hline
\end{tabular}

Berdasarkan data hasil uji coba tes prestasi belajar matmatika siswa dalam bentuk uraian sebanyak lima soal diperoleh hasil sebagai berikut.

Tabel 2 Hasil Validasi Instrumen

\begin{tabular}{ccccc}
\hline Soal & $r_{X Y}$ & $t_{\text {hitung }}$ & $t_{\text {tabel }}$ & Keterangan \\
\hline 1 & 0,414 & 2,530 & & Valid (Sedang) \\
2 & 0,895 & 11,146 & & Valid (Sangat Tinggi) \\
3 & 0,901 & 11,533 & 1,697 & Valid (Sangat Tinggi) \\
4 & 0,823 & 8,060 & & Valid (Sangat Tinggi) \\
5 & 0,901 & 11,576 & Valid (Sangat Tinggi)
\end{tabular}

Setelah melaksanakan validitas instrumen, instrumen juga di analisis reliabilitas untuk menetapkan keajegan instrumen menggunakan alpha cronbach, Adapun rumusnya sebagai berikut.

$r_{11}=\frac{n}{n-1}\left(1-\frac{\sum \delta_{i}^{2}}{\delta_{i}^{2}}\right) \quad($ Suharsimi Arikunto, 2002) 
Keterangan:

$r_{11}=$ Reliabilitas yang dicari

$\mathrm{n} \quad=$ Banyaknya butir soal yang valid

$\sum \delta i^{2}=$ Jumlah varian skor tiap-tiap item

$\delta i^{2} \quad=$ Varians total

Sama seperti validitas, reliabiltas juga diinterprestasikan terlebih dahulu uji-t Berikut rumus uji-t untuk koefisien korelasi sebagai berikut.

$t=\frac{r_{11} \sqrt{n-2}}{\sqrt{1-r_{11}^{2}}}$

Keterangan:

$r_{11}=$ Koefisien korelasi alpha cronbach

$\mathrm{n} \quad$ = Banyaknya subjek yang diuji.

Adapun rumusan hipotesis untuk Reliabilitas sebagai berikut:

Ho $: \rho=0$, artinya soal dikatakan tidak Reliabel.

Ha $: \rho>0$, artinya soal dikatakan Reliabel.

Nilai thitung kemudian dibandingkan dengan nilai $t_{\text {tabel }}$ dengan taraf signifikansi 0,05 dan derajat kebebasan $\mathrm{dk}=\mathrm{n}-2$, dengan kriteria:

Terima Ho dan tolak Ha jika $\mathrm{t}_{\text {hitung }} \leq \mathrm{t}_{\text {tabel }(\alpha, \mathrm{dk})}$, soal tidak Reliabel.

Tolak Ho dan terima Ha jika $\mathrm{t}_{\text {hitung }}>\mathrm{t}$ tabel $(\alpha, \mathrm{dk})$, soal Reliabel.

Untuk mengetahui kategori koefisien reliabilitas digunakan kriteria sebagai berikut.

\section{Tabel 3 Klasifikasi Korelasi Reliabilitas}

\begin{tabular}{cc}
\hline Besarnya "r" & Interpretasi \\
\hline$r_{11} \leq 0,20$ & Derajat reliabilitas sangat rendah \\
$0,20<r_{11} \leq 0,40$ & Derajat reliabilitas rendah \\
$\mathrm{O}, 40<r_{11} \leq 0,60$ & Derajat reliabilitas sedang \\
$0,60<r_{11} \leq 0,80$ & Derajat reliabilitas tinggi \\
$0,80<\mathrm{r} \leq 1,00$ & Derajat reliabilitas sangat tinggi \\
\hline
\end{tabular}

Setelah dilakakukan analisis dengan hasil sebagai berikut.

Tabel 4 Hasil Reliabilitas Instrumen

\begin{tabular}{cccc}
\hline$r_{11}$ & $t_{\text {hitung }}$ & $t_{\text {tabel }}$ & Keterangan \\
\hline 0,86 & 3,65 & 1,697 & Reliabel (Sangat Tinggi)
\end{tabular}


Hipotesis statistik dalam penelitian ini adalah:

Ho : $\bar{x} \leq \mu_{0}$

$\mathrm{Ha}: \bar{x}>\mu_{0}$

Dengan $\mu_{0}$ adalah KKM sekolah yakni 75\%. Dengan Ho adalah Penggunaan Media Pembelajaran Karu Domino tidak efektif untuk mencapai target Hasil Belajar Trigonometri yang Ditargetkan. Sedangakan Ha adalah Penggunaan Media Pembelajaran Karu Domino efektif untuk mencapai target Hasil Belajar Trigonometri yang Ditargetkan.

Langkah-langkah analisis data dalam penelitian ini, sebagai berikut:

1. Uji normalitas digunakan untuk mengetahui apakah populasi berdistribusi normal atau tidak. Pada penelitian ini menggunakan Uji Kolmogorof Smirnov. Adapun langkahlangkah yang dimodifikasi dari Supardi (2013) sebagai berikut :

1) Menentukan taraf signifikan $\alpha=0,05$ dengan hipostesi yang akan diuji adalah

2) Menentukan Hipotesis

$\mathrm{H}_{0}=$ Data berdistribusi normal

$\mathrm{Ha}=$ Data tidak berdistribusi normal

3) Dengan kriteria pengujian:

Jika $\mathrm{a}_{\max }>\mathrm{D}_{\text {tabel }}$ maka tolak $\mathrm{H}_{0}$

Jika $\mathrm{a}_{\max } \leq \mathrm{D}_{\text {tabel }}$ maka terima $\mathrm{H}_{0}$

4) Susun data dari yang terkecil

5) Susunlah frekuensi nilai yang sama.

6) Hitung nilai proporsi $p_{i}=\frac{f_{i}}{n} ; \mathrm{n}=$ banyaknya data.

7) Hitung purposif kumulatif (Kp).

8) Transformasikan nilai data mentah (X) kedalam angka baku (Z) dengan formula:

$z_{i}=\frac{X_{i}-\bar{X}}{s}$

(dengan $\overline{\mathrm{X}}$ dan s masing-masing merupakan rerata dan simpangan baku)

9) Tentukan nilai Ztabel berdasarkan data angka baku (Zi)

10) Hitung niai $\left|a_{2}\right|=K_{p}-Z_{\text {tabel }}$

11) Hitung nilai $\left|\mathrm{a}_{1}\right|=\mathrm{P}-\mathrm{a}_{2}$

12) Cari a maksimum sebagai amax

13) Lakukan pengujian hipotesis dengan cara membandingkan nilai $a_{1}$ dengan $D_{\text {tabel. }}$. 
2 Jika populasi berdistribusi normal maka dilanjutkan dengan menggunakan one sample $t$-test dengan rumus sebagai berikut.

$t_{h}=\frac{\bar{x}-\mu_{0}}{\frac{s}{\sqrt{n}}}$

(Supardi, 2013)

\section{Keterangan :}

$\mathrm{t}_{\mathrm{h}}=$ Harga yang dihitung dan menunjukan nilai standar deviasi dari distribusi $\mathrm{t}$

$\bar{x}=$ Rata-rata nilai yang diperoleh dari hasil pengumpulan data.

$\mu_{0}=$ Nilai yang dihipotesiskan (rata-rata skor ideal atau KKM)

$\mathrm{s} \quad=$ Standar deviasi sampel yang dihitung.

\section{HASIL DAN PEMBAHASAN}

Setelah dilaksanakan treatmen pada kelas eksperimen selanjutnya melaksanakan observasi dengan pelaksanaan ulangan harian dengan soal dari instrumen yang sudah divalidasi sebelumnya. Berikut hasil analisis yang dilaksanakan

1. Uji nomalitas dengan hasil $\mathrm{a}_{\max }=0,036$ dan $\mathrm{D}_{(0,05 ; 24)}=0,269$, karena $\mathrm{a}_{\max }<\mathrm{D}_{\text {tabel }}$ maka terima $\mathrm{H}_{0}$ sehingga populasi diambil dari sampel yang berdistribusi normal.

2. Selanjutnya karena data berdistribusi normal maka dilanjutkan dengan menggunakan one sample $t$-test, diperoleh $t_{\text {hitung }}=3,70$ dan $t_{(0,05 ; 24)}=2,06$. Karena $t_{\text {hitung }}>t_{\text {tabel }}$, maka tolak $\mathrm{H}_{0}$ artinya terdapat penggunaan media pembelajaran kartu efektif untuk mencapai target hasil belajar materi trigonometri yang ditargetkan.

Keberhasilan siswa dalam belajar matematika tergantung pada cara penyajian materi pembelajaran, banyak media pembelajaran dan metode mengajar yang dapat digunakan oleh guru pada proses belajar mengajar matematika. Dalam hal ini juga hendaknya guru harus memotivasi dan memperhatikan minat belajar siswa yang diharapkan dapat meningkatkan kreativitas dan aktivitas siswa dalam belajar, yang pada akhirnya diharapkan dapat meningkatkan prestasi belajar siswa dalam matematika.

Salah satu cara penyajian materi pelajaran matematika yang diharapkan dapat meningkatkan motivasi serta minat siswa untuk belajar matematika sehingga meningkatkan hasil belajar materi trigonometri adalah dengan menggunakan media pembelajaran kartu domino. Penggunaan media pembelajaran kartu domino dapat memberikan kesempatan kepada siswa untuk aktif belajar, dengan cara merubah metode 
pembelajaran yang berpusat pada guru menjadi berpusat pada siswa. Kartu domino disini bukanlah suatu kartu yang digunakan oleh orang untuk berjudi, melainkan suatu media untuk pembelajaran yang bentuknya dibuat seperti kartu domino untuk menarik minat siswa dalam belajar matematika. Konsep Pembelajaran dengan menggunakan media pembalajaran kartu domino lebih menekankan pada cara permainan kartu domino untuk memperoleh suatu kebermaknaan sehingga dapat menimbulkan daya ingat yang lebih tehadap siswa sehingga minat belajar siswa semakin tinggi. Akibat dari meningkatnya motivasi dan menumbuhkan pemahaman siswa dalam belajar matematika serta dapat meningkatkan keaktifan siswa dalam pembelajaran. Oleh karena itu siswa memperoleh hasil belajar materi trigonometri yang baik.

Hal ini dapat dianalogikan bahwa penelitian yang dilaksanakan mendukung teori yang disimpulkan oleh Sundayana (2013) bahwa dengan menggunakan katu domino daya ingat siswa menjadi lebih dan pemahaman siswa pun menjadi lebih paham. Sehingga, Pembelajaran dengan menggunakan media pembelajaran kartu domino efektif untuk mencapai target hasil belajar trigonometri dikarenakan pembelaran tersebut mebuat siswa aktif dan pembelajaran pun semakin menyenangkan untuk siswa.

\section{KESIMPULAN}

Dari keseluruhan penelitian yang dilakukan dapat disimpulkan bahwa penggunaan media pembelajaran kartu efektif untuk mencapai target hasil belajar materi trigonometri yang ditargetkan.

Dari hasil penelitian ini, maka disarankan kepada guru maupun dosen untuk menggunakan media kartu domino sebagai salah satu arternatif untuk mencapai target pembelajaran. Karena adanya keterbatasan dalam penelitian ini, maka penulis menyarankan untuk penelitian lebih lanjut tentang penggunaan media pembelajaran kartu domino, agar dilakukan dengan jumlah sampel yang lebih banyak, alokasi waktu penelitian yang lebih lama, serta dilakukan pada pokok bahasan yang lainnya.

\section{DAFTAR PUSTAKA}

Komandoko, G. (2009). Jari-Jari Hitung. Yogyakarta: Citra Pustaka.

Sadiman, A. S. (2003). Media Pendidikan. Jakarta: Grafindo Persada.

Slameto. (2003). Belajar dan Faktor-Faktor yang Mempengaruhinya. Jakarta : Rineka Cipta.

Subandi. (2004). Belajar dan Pembelajaran Teori dan Aplikasinya. Indramayu: FKIP 
100 Efektivitas Penggunaan Media Kartu Domino untuk Mencapai Target Hasil Belajar Trigonometri

UNWIR Pers.

Sundayana, R. (2013). Media dan Alat Peraga dalam Pembelajaran Matematika.

Bandung: Alfabeta.

Supardi. (2013). Aplikasi Statistik Dalam Penelitian. Jakarta: Change Publication. 